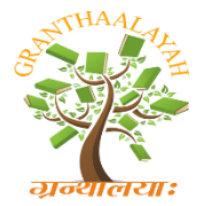

\author{
INTERNATIONAL JOURNAL OF RESEARCH - \\ GRANTHAALAYAH \\ A knowledge Repository
}

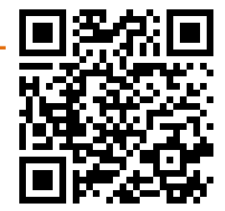

Science

\title{
ELECTRICAL BEHAVIOR OF HYBRID BLEND REINFORCED BY FIBERS WITH DIFFERENT MIXING RATIOS
}

\author{
Mustafa A. Rajab ${ }^{1}$, Maher N. Abdullah ${ }^{2}$, Sabah A. Salman *3 \\ ${ }^{1}$ Technical Institute of Baqubah, Middle Technical University, Iraq \\ ${ }^{2,}{ }^{* 3}$ Department of Physics, College of Science, University of Diyala, Iraq
}

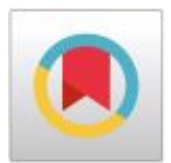

\begin{abstract}
One has to realize that the best design for cars, aircraft or parts of machines is to be able to carry the loads and conditions of service, from here to the composite materials to combine two or more materials that often have completely different properties Which work together (those materials) to give unique vehicle properties, to be used in electrical, thermal and environmental applications. The composite materials used in the research on epoxy and phenol formaldehyde resins have been mixed in different proportions and then reinforced with carbon fibers, fiberglass and Kevlar fibers to demonstrate the effect on both Electrical conductivity and Electrical dielectric.
\end{abstract}

Keywords: Hybrid Blend; Mechanical Behavior; Fibers; Electrical Behavior; Mixing Ratio.

Cite This Article: Mustafa A. Rajab, Maher N. Abdullah, and Sabah A. Salman. (2019). "ELECTRICAL BEHAVIOR OF HYBRID BLEND REINFORCED BY FIBERS WITH DIFFERENT MIXING RATIOS." International Journal of Research - Granthaalayah, 7(7), 93-101. https://doi.org/10.29121/granthaalayah.v7.i7.2019.720.

\section{Introduction}

The electric field causes deformation or translation of the originally symmetrical distribution of the electron clouds of atoms or molecules. This is basically the displacement of the outer electron clouds with respect to the internal positive atomic cores [1]. This effect is shared to all materials. This polarization effect is small, despite the vast number of atoms within the material, since the moment arm of the dipoles is very short, which maybe comprises only a small fraction of an angstrom [2].The electric field reasons the ions or atoms of a polyatomic molecule to be displaced relative to each other. This is essentially the distortion of the normal lattice vibration, and this is why it is sometimes denoted to as vibrational polarization. Ionic displacement is common in ceramic material [3]. Orientation (dipolar polarization) polarization this polarization occurs only in materials consisting of particles or molecules with a permanent dipole moment. The electric field reasons the reorientation of the dipoles toward the direction of the field [4].interfacial polarization or the space charge, produce by the separation of movable positively and negatively charged particles under an imposed field, which form negative and positive space charges in the bulk of the material or at the interfaces between different materials. These space charges, in turn, modify 
the field distribution. This occurs mainly in polycrystalline solids or amorphous or in materials consisting of traps as shown in figure (1) [5].

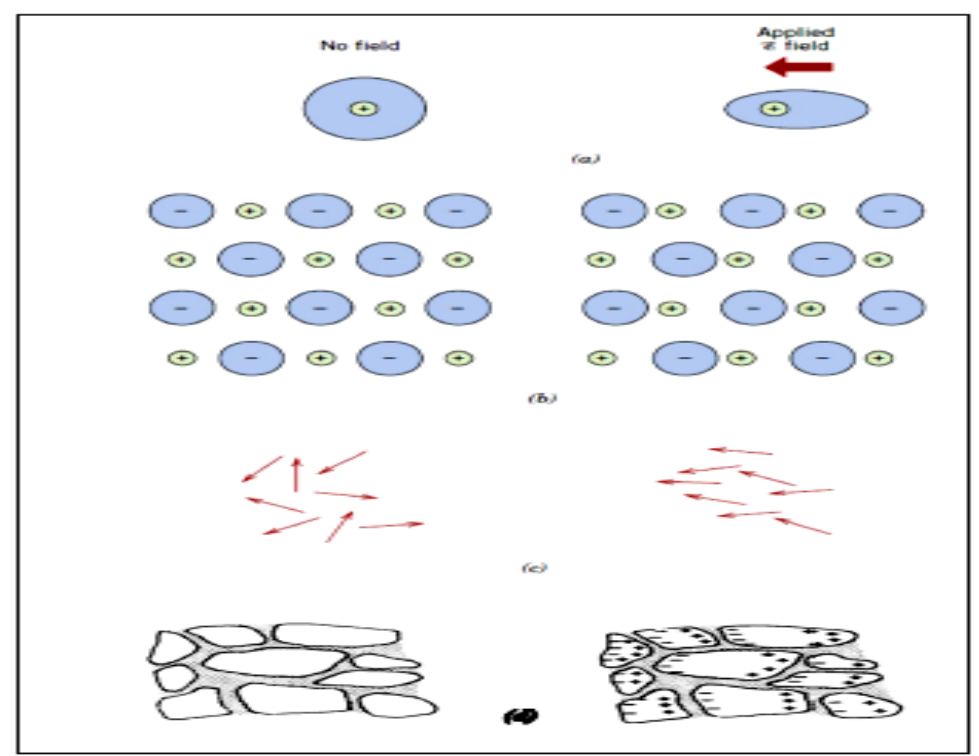

Figure 1: Basic kinds of electric polarization: (a) electronic polarization, (b) atomic or ionic polarization, (c) dipolar polarization and (d) interface or space charge polarization [5].

The difference of the dielectric constant with frequency is similar to the difference of polarizability and polarization. At low frequencies of the order oaf few $\mathrm{Hz}$, the dielectric constant is made up of contributions from electronic, atomic and space charge polarization [6]. When measurements are carried out as a function of frequency, the space charge polarization ends after a certain frequency and the dielectric constant becomes frequency independent. The frequency beyond which the variation ends may fall in the certain range. The frequency-independent value is taken as the true static dielectric constant [7].By measuring the dielectric constant as a function of frequency, one can discrete the different polarization components. Each polarization mechanism has a bounding properties frequency. Electrons have very small mass and are therefore able to follow high frequency fields up during the optical range. Ions are a thousand times heavier but continue to follow fields up to the infrared range. Molecules-especially those in liquids and solids are heavier yet and are severely constraining by their surroundings. Most rotational effects, like those in water, are bounded to microwave frequencies. Space charge effects are often in the kilohertz range or even lower Frequency has a significant effect on the polarization mechanisms of a dielectric. When the frequency of the imposed field is quite large as compared to the inverse of the relaxation time for a particular polarization process, the contribution of that process to the polarizability is negligible. As relaxation time is maximum for the space charge polarization, the space polarization vanishes first followed by dipolar, ionic, and electronic contributions [8].The polymer matrix composites classified as insulators. The electrical response for polymer matrix nano composites refers to their conductivity and dielectric performance. Since the primary electrical character of polymers is insulating, polymer composites seem to be dielectrics, (which can be polarized under the effect of an external electric field). Considering the character of the employed nano filler or nano inclusions, polymer nanocomposites categorizes in two major classified: first the insulating matrix-dielectric reinforcing phase and second the insulating matrix-conductive reinforcing phase. The nature of the nano filler will defers in kinds, shape, and properties where it could be organic, 
inorganic, conductive, insulation, spherical, non-spherical [9].In considering the influence of the insertion of nanoparticles in an insulator there are two essential factors to take into account. First, the effect of nanoparticles happened on the physical and chemical structure of the material. Second, how the nanoparticles changed the electrical properties of the material surrounding it. The percolation effects characterized by increasing in electrical conductivity by several orders of magnitude. This interaction zone may overlap giving rise to effects related with percolation through the interaction zone as shown in figure (2) [10].

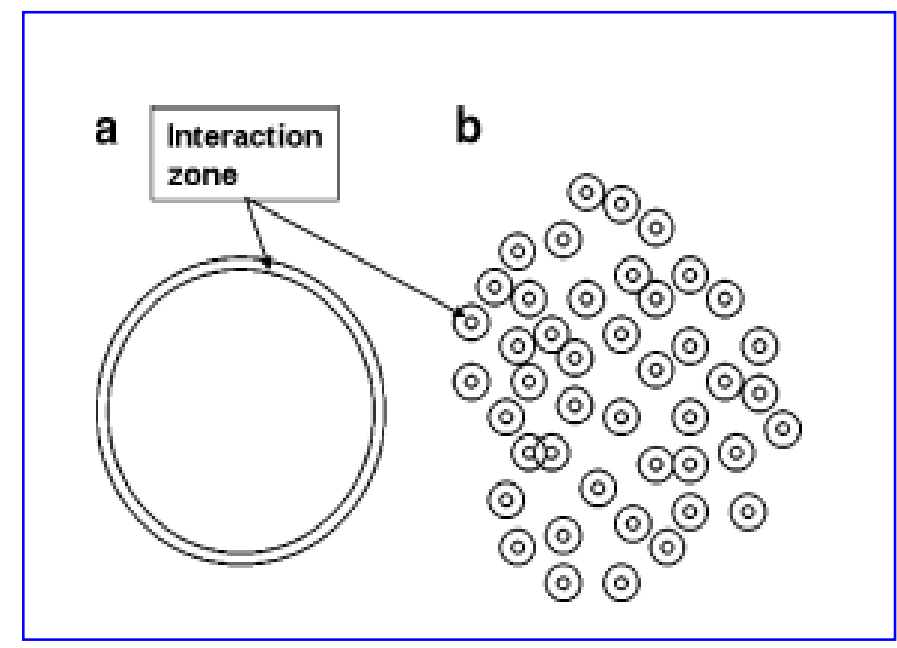

Figure 2: Illustration of interaction zones for (a) a micropaticles and (b) an assembly of nanoparticles [10].

The study of properties under the influence of forces and loads in different conditions is of great importance to determine the suitability of these properties to the work place of composite materials. The epoxy mixture was used with formaldehyde resins and different percentages to show the effect on both electrical conductivity and dielectric. Carbon, fiberglass and Kevlar fibers to demonstrate the effect on both the electrical conductivity and dielectric, and then analysis and compare with previous results.

\section{Materials and Methods}

Epoxy resin (LEYCO-POX 103), phenol formaldehyde (resole) resin.

Samples Preparation and Calculation of Electrical Parameters: epoxy and phenol formaldehyde resins were mixed with different weight fractions.

Epoxy resin (EP): as a matrix (Sikadur -52 LP is a two component, component A solvent-free, low viscosity injection-liquid, based on high strength epoxy resin and hardener component B from Sikadur-52 LP) as shown in figure (3). The mixing ratio for resin component A and hardener component $\mathrm{B}$ is $(\mathrm{A}: \mathrm{B}=2: 1)$ parts by volume and weight and pot life $(2 \mathrm{Kg}),(30$ minute $)$ of L.P. type and viscosity $(130 \mathrm{mPa} . \mathrm{s})$ at $\left(30^{\circ} \mathrm{C}\right)$. Table (1) shows the properties and specifications of raw materials used in the preparation of samples. 


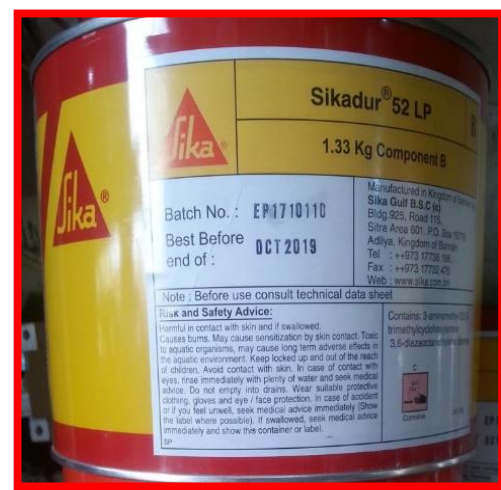

(a)

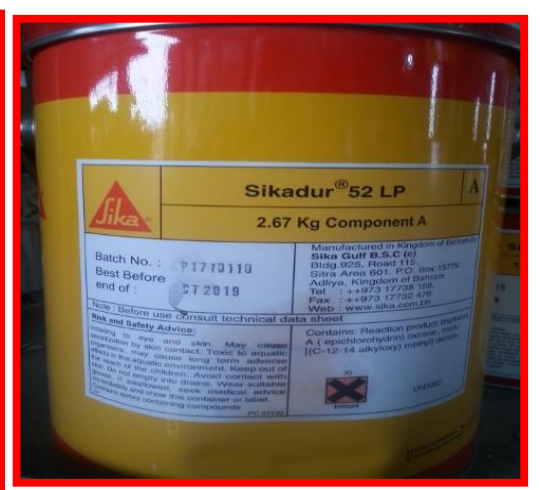

(b)

Figure 3: (a) epoxy resin component A Sikadur-52 LP and (b) hardener component B from Sikadur-52 LP.

Table 1: Resin materials and some of their properties.

\begin{tabular}{|l|l|l|}
\hline Specifications & Epoxy & Phenol Formaldehyde \\
\hline Appearance & $\begin{array}{l}\text { Comp. A: yellowish } \\
\text { Comp. B:brownish }\end{array}$ & Pale brown liquid \\
\hline Solid content & & $50 \%-52 \%$ \\
\hline Celatin at $\left(130^{\circ} \mathrm{C}\right)$ & $1.11-1.18 \mathrm{gm} / \mathrm{c} . \mathrm{c}$ & $10-15 \mathrm{~min}$ \\
\hline Specific gravity & & $1.15-1.20 \mathrm{gm} / \mathrm{c} . \mathrm{c}$ \\
\hline PH & & $8.0-8.5$ \\
\hline Water tolerance & Infinite \\
\hline Free phenol content & 250(mPa.s) & $1.0-1.5 \%$ \\
\hline Free formaldehyde content & $\begin{array}{l}\text { Comp.A+B:1.1 } \mathrm{Kg} / \mathrm{l} \\
\text { (mixed) }\end{array}$ & $1.21 \mathrm{Kg} / \mathrm{l}$ \\
\hline Viscosity at $\left(25^{\circ} \mathrm{C}\right)$ & 12 month & 45 days from the manufacture \\
\hline Density $\left(20^{\circ} \mathrm{C}\right)$ & 60 min & \\
\hline Shelf- life at $\left(25^{\circ} \mathrm{C}\right)$ & $\begin{array}{l}\text { Compressive }=53 \mathrm{~N} / \mathrm{mm}^{2} \\
\text { Flexural }=50 \mathrm{~N} / \mathrm{mm}^{2} \\
\text { Tensile }=25 \mathrm{~N} / \mathrm{mm}^{2}\end{array}$ & \\
\hline Pot life $(2 \mathrm{~kg})$ at $\left(20^{\circ} \mathrm{C}\right)$ & $89 \times 16^{-6}$ per $(-20 \text { to } 60)^{\circ} \mathrm{C}$ & \\
\hline $\begin{array}{l}\text { Mechanical strength } \\
\text { at }\left(20^{\circ} \mathrm{C}, 10 \text { days }\right)\end{array}$ & $\begin{array}{l}\text { Coefficient of thermal } \\
\text { expansion }\end{array}$ & \\
\hline
\end{tabular}

The fibers reinforcement materials are:

1) Glass fibers (E-glass fibers, glass fibers Biaxial Fabric 0/90), the basis of textile-grade glass fibers is silica, $\left(\mathrm{SiO}_{2}\right)$.

2) Carbon fibers precursors for the production of carbon fibers include polyacrylonitrile (PAN), isotropic pitch, mesosphere pitch, and regenerated cellulose, among others.

3) Kevlar fibers (kevlar-49 fibers), materials used as thermoplastic matrix are: (i) P1 thermoplastic (styrene acrylonitrile), (ii) P2 - ASTALAC@ ABS (acrylonitrile butadienestyrene) 2029-2 and (iii) P3 - DOWLEX® polyethylene resins. The fibers materials used in this work as shown in figure (4) and table (2) shows the propertiesof these fibers. 


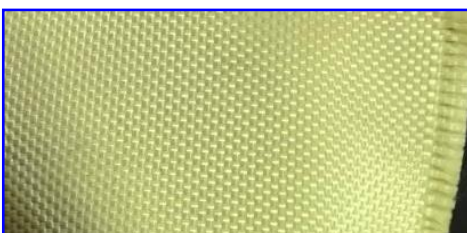

(a)

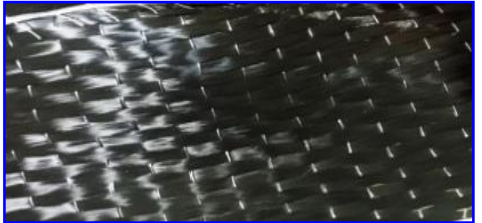

(b)

Figure 4: (a) kevlar-49 fibers, (b) carbon fibers and (c) E-glass fibers.

Table 2: Property of fibers.

\begin{tabular}{|l|l|l|l|l|}
\hline Property & $\begin{array}{l}\text { Tensile } \\
\text { Strength }\end{array}$ & Compressive Strength & Elastic Modulus & $\begin{array}{l}\text { Density } \\
\text { (g/cm3) }\end{array}$ \\
\hline E-glass fibers & $3445(\mathrm{MPa})$ & $1080(\mathrm{MPa})$ & $73(\mathrm{GPa})$ & 2.58 \\
\hline Carbon fibers & $(3-7 \mathrm{GPa})$ & $(1-3 \mathrm{GPa})$ & $(200-935 \mathrm{GPa})$ & $1.75-2.20$ \\
\hline Kevlar fibers & $2757.9(\mathrm{MPa})$ & $517.1(\mathrm{MPa})$ & $151.7(\mathrm{GPa})$ & $1467(\mathrm{~kg} / \mathrm{m} 3)$ \\
\hline
\end{tabular}

\section{Composites Preparation}

Hand-held technique was used to prepare sheets of pureor reinforced epoxy materialwith many types of fibers. The casting mold consists of glass plates with dimensions ( $200 \times 200 \times 4 \mathrm{~mm})$ and under the casting mold puttednylon sheets to prevent adhesion of the composite material as shown in figure (5). All the test specimens are finished by abrading the edges on a fine carborundum paper.

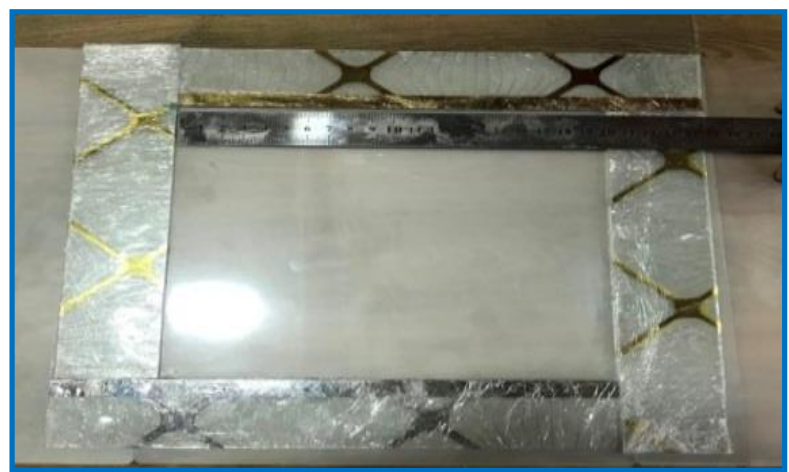

Figure 5: The casting mold consists of glass plates with dimensions (200 x $200 \times 4 \mathrm{~mm})$.

Neat epoxy preparation; firstly epoxy resin and hardener are weighted for suitable mixing ratio, and manually mixed then epoxy resin and hardener were mixed by magnetic stirrers at ( $800 \mathrm{rpm}$ ) for (15 minute) to have good homogeneous between epoxy resin and hardener.Epoxy risen and resol resin preparation; firstly epoxy resin and resol resin are weighted for suitable mixing ratio and manually mixed then epoxy resin and resol resin were mixed by magnetic stirrers at $(800 \mathrm{rpm})$ for (15 minutes) and finally add the hardener with suitable mixing ratio to have good homogeneous of hybrid resin as shown in table (3).

Table 3: Hybrid blend mixing ratio of epoxy risen and resole resin.

\begin{tabular}{|l|l|l|}
\hline No. & Mixing Ratio of Epoxy Resin & Mixing Ratio of ResoleResin \\
\hline 1 & $100 \%$ & $0 \%$ \\
\hline 2 & $95 \%$ & $5 \%$ \\
\hline 3 & $90 \%$ & $10 \%$ \\
\hline
\end{tabular}




\begin{tabular}{|l|l|l|}
\hline 4 & $85 \%$ & $15 \%$ \\
\hline 5 & $80 \%$ & $20 \%$ \\
\hline 6 & $70 \%$ & $30 \%$ \\
\hline 7 & $60 \%$ & $40 \%$ \\
\hline 8 & $50 \%$ & $50 \%$ \\
\hline
\end{tabular}

Physical tests samples: Hand-held technique is used to make reinforced epoxy board with fiber matting types: kevlar fibers, carbon fibers and glass fibers.

First: the mold made of glass panels with dimensions of $(20 \times 15 \mathrm{~cm})$ thickness of $(4 \mathrm{~mm})$ and repaired by Glue Gun, a mold that was placed on the sheets of nylon to prevent the adhesion of the sample.

Second: epoxy resin + phenol formaldehyde resins. Mix (95\%) of the epoxy resins with (5\%) resole resins manually and then mix with the stirrer by magnetic stirrer at ( $800 \mathrm{rpm})$ for $(15 \mathrm{~min})$ to obtain a good homogeneity between hybrid and crucified resin and remove the trapped air bubbles in the sample. The weighted part of the materials used was obtained by weighing the kevlar fibers, carbon fibers and glass fibers into the mixed resin mixture. The mold was uniformly spread by hybrid resin, and the first layer of mats was placed above it and was published by hybrid resin. After the second layer, a serrated steel cylinder was used to roll the cloth before placing a hybrid resin. The casting was done at room temperature for ( 24 hours). They have finally been removed from the mold to get a fantastic vehicle plate.

\section{Dielectrical Tests Samples}

The final samples shape prepared for dielectrical test identical to the specification of ASTM (D $150)$ thediameter was $(2.1 \mathrm{~cm})$ as in illustration in figure (6).

\begin{tabular}{|l|}
\hline 100\% Epoxy resin \\
\hline $95 \%$ Epoxy Resin $+5 \%$ Resol Resin \\
\hline $90 \%$ Epoxy Resin $+10 \%$ Resol Resin \\
\hline $\begin{array}{l}\text { 95\% Epoxy Resin }+5 \% \text { Resol Resin } \\
+ \text { Glass fibers }\end{array}$ \\
\hline 90\% Epoxy Resin $+10 \%$ Resol Resin \\
\hline
\end{tabular}

Figure 6: Dialectical tests samples. 


\section{Results and Discussions}

\subsection{Dielectric Constant}

\section{Frequency Dependence}

Frequency dependence: It can be seen from figure (7) that the dielectric constant of unfilled epoxy and epoxy composites decrease with an increasing frequency. Dielectric constant is a frequency dependence parameter in polymer systems. In atypical epoxy system based on an epoxy resin cured with a hardener as in the present case, the epoxy component of dielectric constant is governed by the number of oriental dipoles present in the system and their ability to orient under an applied electric field.

Usually, the molecular groups which are attached perpendicular to the longitudinal polymer chain contributed to the dielectric relaxation mechanism. At lower frequencies of applied voltage, all the free dipolar functional groups in the epoxy chain can orient themselves resulting in a higher dielectric constant value at these frequencies. As the electric field frequency increases, the bigger dipolar groups find it difficult to these dipolar groups to the dielectric constant goes on reducing resulting in a continuously decreasing dielectric constant of the epoxy system at higher frequencies. Similarly, the inherent dielectric constants in glass fibers also decrease with increasing frequencies of the applied field. This combined decreasing effect of the dielectric constant for both epoxy and the filler result in a decrease in the dielectric constant of the epoxy composites also when the frequency of the applied field increases [7].

\section{Wight Fraction Dependence}

As shown in the same figure, we can see that the dielectric constant increase as the volume fraction of fillers in the polymer matrix is increased because of the system becomes more heterogeneous than the pure epoxy as more filler is added to it. The increase in dielectric constant with increase in filler is attributed to the formation of clusters. A cluster may be considered as a region in the polymer matrix where particles are in physical contact or very close to each other. The average polarization associated with a cluster is larger than that of an individual particle because of an increase in the dimensions of the metallic inclusion and, hence, greater interfacial area [9].

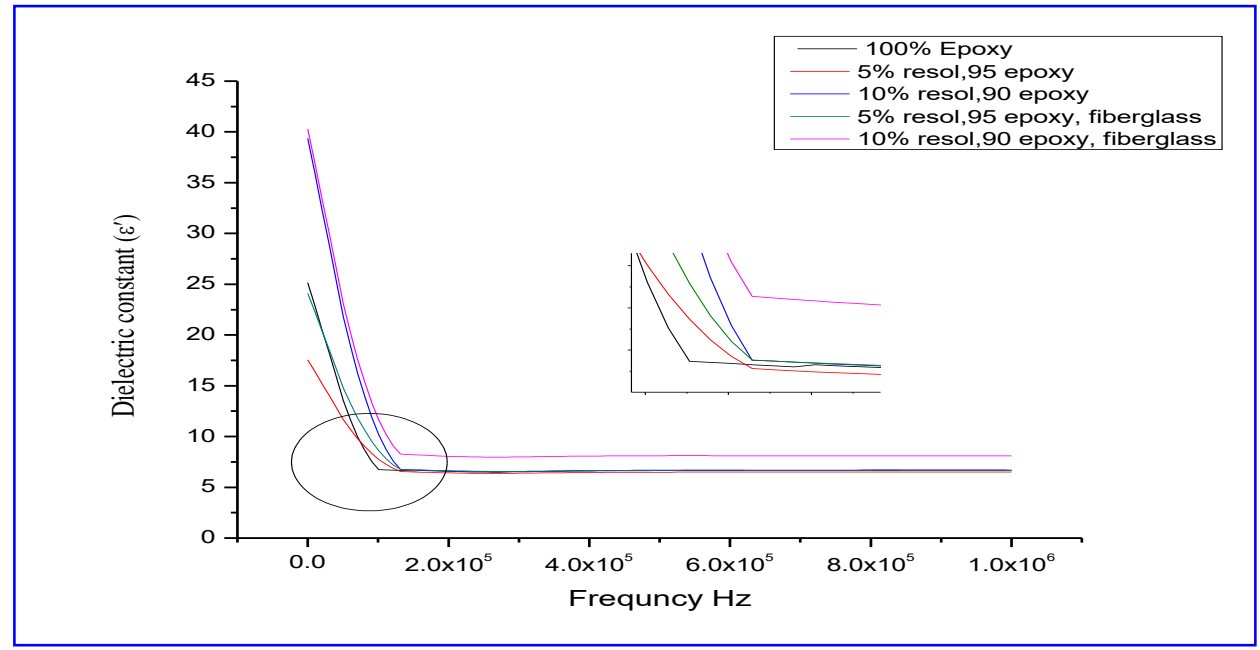

Figure 7: The relationship between dielectric constant and frequency. 


\subsection{Electrical Conductivity}

\section{Frequency Dependence}

The variation in electrical conductivity of the composites as a function of frequency is shown in figure (8). The electrical conductivity slowly increases as the frequency is increased in range (100 $\mathrm{Hz}-400 \mathrm{KHz}$ ). The interpretation of this behavior may be that the composite materials are basically attributed to high dislocation density near the interface. Electrical conductivity in turn depends on the number of charge carriers in the bulk of the material, the relaxation time of the charge carriers and the frequency of the applied electric field [5].

\section{Weight Fraction}

The general theory to explain the conduction mechanism of fillers (fibers) filled polymer composites is the "theory of conductive paths", which suggests that it is the existence of conductive paths (fibers) that results in the conductivity of the composites. With increasing of the content of the fillers, conductive paths among the fillers increase, and the average distance between the fillers becomes smaller; thus, the resistivity of the composites decrease and increase the electrical conductivity [4].

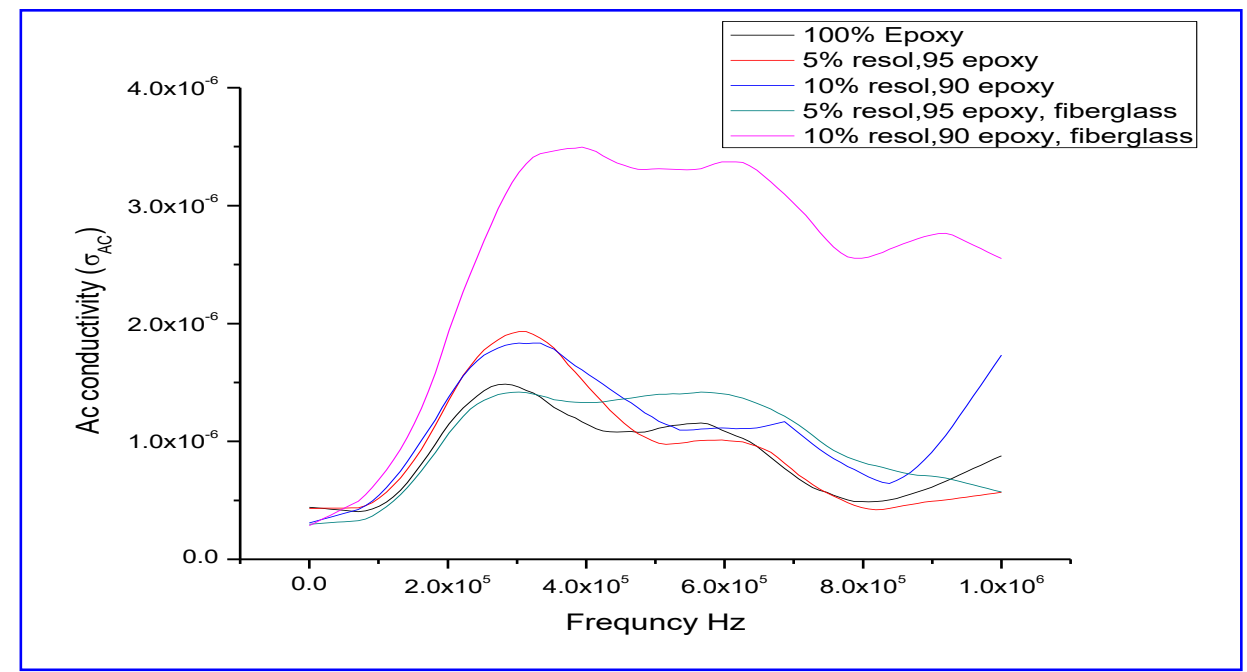

Figure 8: The relationship between A.C conductivity and frequency.

\section{Conclusions}

1) The electrical insulation constant for epoxy and rheumatoid non-fibers compounds decreases with increasing frequency.

2) All free bipolar functional groups in the epoxy chain are routed the same, leading to high value of the static insulation at low voltage frequencies applied.

3) The glass fibers dielectric constant decreases with the frequency increase in the applied field. This decreasing effect with the insulation constant for both epoxy and filler leads to a decrease in the insulation constant of the composite material when the applied field frequency increases.

4) The dielectric constant increases with the increase of the volumetric fraction of the padding because the system becomes more homogenous, and the increase in the dielectric constant leads to the formation of groups, which are in close contact with each other. 
5) The presence of conductive paths (fibers) leads to the delivery of vehicles, where the paths connecting the fillings increase, the average distance between the fillings becomes smaller and thus the resistance of the composite material decreases and increases the electrical conductivity.

\section{References}

[1] 1-M. A. Rajab, E. I. Kader, A. A. Hamod andAbd-H. I. Hameed,"Mechanical Properties of Silica, Graphite AndCarbon FibersReinforced Composites", International Journal of Engineering and Technology (IJET), V. (9), N (5),pp. 3532-3535,(2017).

[2] M. A. Rajab, A. A.Hammod, E. I. Kader andAbd-H. I. Hameed,"Mechanical Properties (Tensile, Hardness and Shock Resistance) for the Phenol Formaldehyde Resin with Epoxy Resin", Diyala Journal of Engineering Sciences, Vol. 4,No. (1) , pp. 55-60,(2018).

[3] J. Zheng, "Studies of Resole/Isocyanate Hybrid Adhesives", Ph.D., Thesis, Virginia Polytechnic InstituteAnd State University, (2008).

[4] M. A. Rajab, A. A.Majeed and T. G.Shaalan, "Damping Properties of Composite Materials Reinforced by Silica, Graphite and Carbon Fibers", IOSR Journal of Mathematics (IOSR-JM), V. (14), N (4), Ver. IV, pp. 22-25, (2018).

[5] P. K. Mallick, "Fiber-Reinforced Composites: Materials, Manufacturing and Design", 3rd Edition, CRC Press, (2007).

[6] A. A. Al-Jeebory, A. I.Al-Mosawi, S. A. Abd-Allah, "Effect of percentage of Fibers Reinforcement on Thermal and Mechanical Properties for Polymeric Composite Material", Iraqi Journal of Mechanical and Materials Engineering, First Conference of Engineering College, (2009).

[7] E.P.D.Garmo, J.T. Blackand R.A. kohser, "Materials and processes in Manufacturing", 10th Edition,John Wiley \& Sons, (2008).

[8] H. A.Hoby, "Improvement Properties of Reinforced Plastic Materials", M.SC. Thesis, Engineering College, Babylon University, Iraq, (1999).

[9] F.P. Incroperaand D.P.Dewitt, "Introduction to Heat Transfer", 3rd Edition, John Wiley \&Sons, (1996).

[10] M. N. Abdullah, M. A. Rajab and S. A. Salman, "Using Epoxy-Phenol Formaldehyde Hybrid BlendAs an Alternative to the Materials used in the Manufacture of the Oil Pan in the Vehicle's InternalCombustion Engine", Indian Journal of Natural Sciences (IJOS), V.(9), N.(52), pp. 16836 $-16841,(2019)$.

\footnotetext{
*Corresponding author.

E-mail address: pro.dr_sabahanwer@yahoo.com
} 